\title{
Prólogo "Homenaje a Joan Noguera Tur"
}

\author{
Javier Esparcia Pérez, Joan Manuel del Alcázar Garrido, y Adrián \\ Ferrandis Martinez (Editor invitado)
}

\section{EL INICIO: UNA PROMETEDORA Y SÓLIDA CARRERA PROFESIONAL. POR JAVIER ESPARCIA PÉREZ}

Querido Joan.

Un día de junio de 1992, un chaval joven llamó a la puerta de mi despacho, en el Departamento de Geografía de la Universidad de Valencia. Ya prácticamente había acabado el curso. Era la primera vez que lo veía. Me dijo que había preguntado a uno de sus profesores, Juan Romero, porque tenía interés en hacer alguna investigación sobre cuestiones rurales. Juan le había indicado que hablase conmigo.

Le invité a sentarse, y estuvimos hablando más de media hora. Me causó una grata impresión. Aquel chaval destacaba por su madurez, su disponibilidad por el trabajo y, sobre todo, con un entusiasmo desbordante, con muchas ganas por aprender y hacer cosas.

Han pasado casi 30 años, pero recuerdo muy bien aquel día (es como esas imágenes que se quedan, sin saber por qué). Nunca se sabe qué va a ocurrir cuando conoces a alguien, pero aquel chaval se convirtió en mi primer discípulo y, sobre todo, un gran amigo. Eras tú, mi querido Joan. Efectivamente, aquel fue el principio de una larga amistad, y de una carrera profesional juntos.

Por aquel entonces yo estaba participando en una propuesta para un proyecto europeo ("Improving the Economic Impact of Public Institutions on Lagging Rural and Coastal Regions"). Fue aprobada por la Comisión Europea, incluyendo financiación para contratar a un investigador. No tuve dudas de que tú eras el candidato idóneo para cubrir aquella plaza, y te hiciste con ella. Recuerdo que tú ya tenías un destacado dominio del inglés, lo cual vino muy bien en unos proyectos en los que el inglés se utilizaba cada vez más, pese a la aún importante presencia del francés (tal vez recodarías al colega Roger Calmes, exigiendo que se hablase igualmente en francés).

Aquel proyecto fue nuestra primera experiencia europea conjunta. Un verdadero aprendizaje para los dos, pero también aprendizaje mutuo, porque durante el proyecto, a raíz del proyecto, y con el material que íbamos generando, íbamos también trabajando en lo que sería tu tesis doctoral. A la sazón, decidimos proponerle al coordinador, el profesor Gordon Clark (Lancaster University), que fuese codirector. Así es como tu tesis, centrada en la evaluación de políticas públicas de desarrollo rural, fue un aprendizaje y especialización conjunta. Aunque el proyecto lo habíamos acabado en 1996, y estabas ya colaborando en otros proyectos, continuaste con la tesis, hasta su finalización en 1999. Hiciste un gran esfuerzo, manteniendo tu compromiso con el proyecto de turno mientras colaborabas en el proyecto Regional Images and the Promotion of Quality Products and Services in the Lagging Regions of the European Union (RIPPLE), entre 1997 y 1999. 
Recuerdo bien que te fui presionando cada vez más (y también liberando de otras tareas) para que pudieses acabarla. Me pareció una excelente idea aquella estancia en Maine. Te iba a servir para acabarla, y cumpliste brillantemente con el objetivo. A partir de ahí ya pudiste centrarte más en nuestras investigaciones, como por ejemplo el proyecto que me traje de mi estancia en Cheltenham, con el excelente profesional, y mejor amigo, Malcom Moseley, que me consta también lo ha sido tuyo. En el marco de este Proyecto, Partnerships for Rural Integrated Development in Europe (PRIDE) (entre 1999 y 2001), hicimos un excelente trabajo, con la inestimable colaboración "local" de la compañera y también común amiga Almudena Buciega.

Posteriormente conseguimos otro proyecto, Aspatial Peripherality, Innovation and the Rural Economy (ASPIRE), entre 2001 y 2004. Yo conocía de proyectos previos a su coordinador, Andrew Copus, con el que también mantuvimos una estrecha relación profesional.

Los proyectos de investigación eran solo una parte de la intensa actividad profesional que compartíamos. No puedo olvidarme del intenso y fructífero trabajo que hiciste cuando diseñamos y pusimos en marcha el curso de especialización para Agentes de Empleo y Desarrollo Local, que pronto derivó en el Master en Promoción y Gestión del Desarrollo Local. Esta oferta formativa fue la referencia para toda una generación de AEDL en la Comunidad Valenciana, y ahí también tuviste un papel muy relevante. Los materiales que ahí compilamos siguen siendo hoy una referencia en ese ámbito profesional.

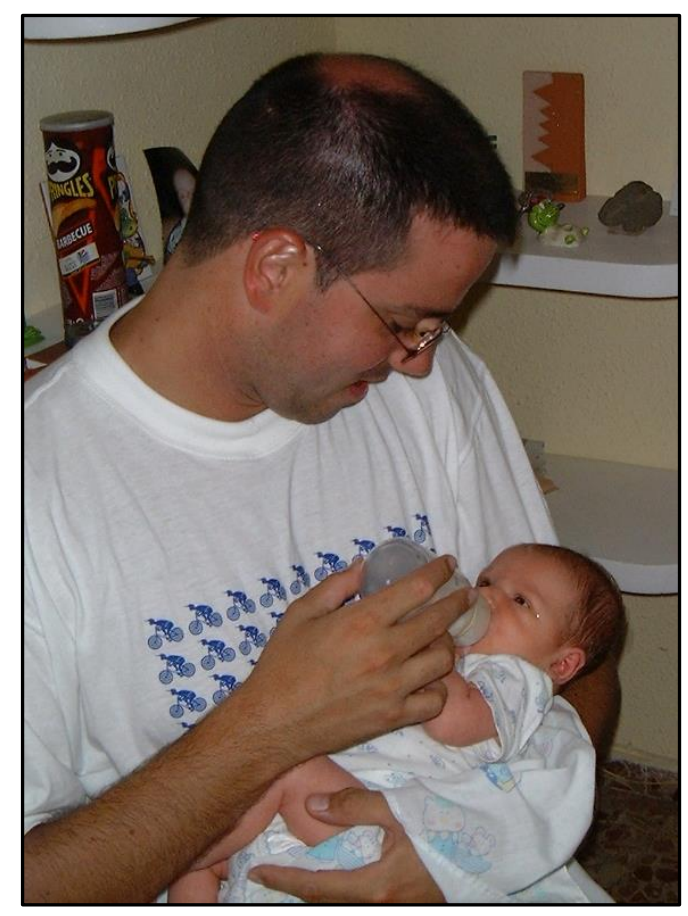

Entrelazando caminos. Autor: Javier Esparcia

Me has acompañado en el proceso de especialización que había iniciado en 1985, sobre cuestiones rurales, y que tú abrazaste con entusiasmo. Y recuerdo bien el día que, en el bar de la Facultad de Geografía e Historia, dimos nombre al grupo de investigación, la Unidad de Desarrollo Rural y Evaluación de Políticas Públicas (UDERVAL). Tú no fuiste uno más. Fuiste protagonista principal del diseño y puesta en marcha del grupo de investigación, en el que creciste y maduraste profesionalmente. Todos esos proyectos, 
trabajos aplicados y ofertas formativas fueron fruto, en gran parte, de tu trabajo, sin olvidar a otros compañeros, en especial, en aquellos años, a María Dolores Pitarch, a Almudena Buciega, a Dolores Pérez, a Carmen Pastor, a Maite Moreno, a Vicente Ferrer, o a Jenaro Parra, entre otros.

Querido Joan. Te estoy enormemente agradecido por haberme acompañado tan estrechamente durante mis 15 primeros años de mi vida profesional, y buena muestra de esa comunión tan estrecha son todas nuestras publicaciones conjuntas. Pero me quiero quedar con algo más, mucho más importante, con las tres décadas de amistad, de saber que ahí he tenido y sigo teniendo un amigo, bueno, leal y sincero.

Recuerdo bien una conversación sobre las cosas de la vida, en la que decías que "si tú das, la vida te lo devuelve". Y tú has sido siempre una persona que ha dado, y por eso me considero un privilegiado porque, también a mí, me has dado, y mucho. Y por ello siempre te estaré agradecido.

Pero la vida, a veces, no es justa. No lo está siendo contigo, al retirarte demasiado pronto de una prometedora y sólida carrera profesional. Y por supuesto no lo está siendo con todos los que te queremos, al privarnos de ti, tal como te hemos conocido, con el Joan con el que tanto hemos compartido.

Escribiendo estas líneas no puedo por menos que acordarme, y mucho, de las contradicciones que nos depara la vida a veces. Como bien sabes, en el año 1999 perdimos a la que era nuestra referencia profesional (y también un muy buen amigo) José María Bernabé. Era demasiado pronto, por supuesto para él, pero también para sus discípulos, entre los que me encontraba. Y ahora, mi primer discípulo, mi querido Joan, también has sido cruelmente apartado de nuestra vida diaria.

Ni a los maestros ni a los discípulos se olvida nunca, y por eso tú estarás siempre en mi recuerdo. Pero quiero quedarme con lo importante, con el hecho de que aquel mi primer discípulo ha sido un gran amigo durante más de treinta años. Mi querido Joan, ha sido todo un privilegio tenerte a mi lado y contar con tu amistad. Muchas gracias. Un fuerte abrazo.

Javier Esparcia

10 de julio de 2021 


\section{JOAN NOGUERA, DE LO LOCAL A LO GLOBAL SIN FRONTERA RECONOCIBLE. POR JOAN MANUEL DEL ALCÁZAR GARRIDO}

Joan Noguera pertenece, académicamente hablando, a una generación de profesores posterior a la mía. De hecho, no nos conocíamos personalmente hasta que nuestro colega y común amigo Joan Romero nos presentó. Por aquel entonces la Universitat de València había decidido instalarse de forma permanente en Gandia, como una experiencia que se sustentaba en las dos décadas que llevaba en funcionamiento la Universitat d'Estiu. Nos habíamos puesto a trabajar desde 2003 para que nuestra presencia en La Safor no se limitara a una quincena veraniega, sino que la actividad académica se mantuviera en marcha durante todo el año.

La buena acogida de aquella aventura emprendida de forma cómplice por el equipo rectoral de Francisco Tomás y el gobierno municipal de coalición presidido por José Manuel Orengo, que había determinado un incremento sustantivo del trabajo y de la responsabilidad institucional en la ciudad saforenca, cristalizó en un incremento de la plantilla del personal de lo que se llamaría Centre Internacional de Gandia, así como en el nombramiento de un subdirector.

Joan Noguera fue la persona ideal para ocupar ese puesto. Que fuera hijo y vecino de Gandia, además de experto conocedor de la comarca, lo hacía particularmente adecuado, pero lo que verdaderamente hizo de él la persona inmejorable para el cargo fue su entrega y su capacidad de trabajo, así como su inalterable bonhomía y su disposición irrenunciable al diálogo como llave maestra para resolver cualquier tipo de conflicto, para superar cualquier tipo de obstáculo.

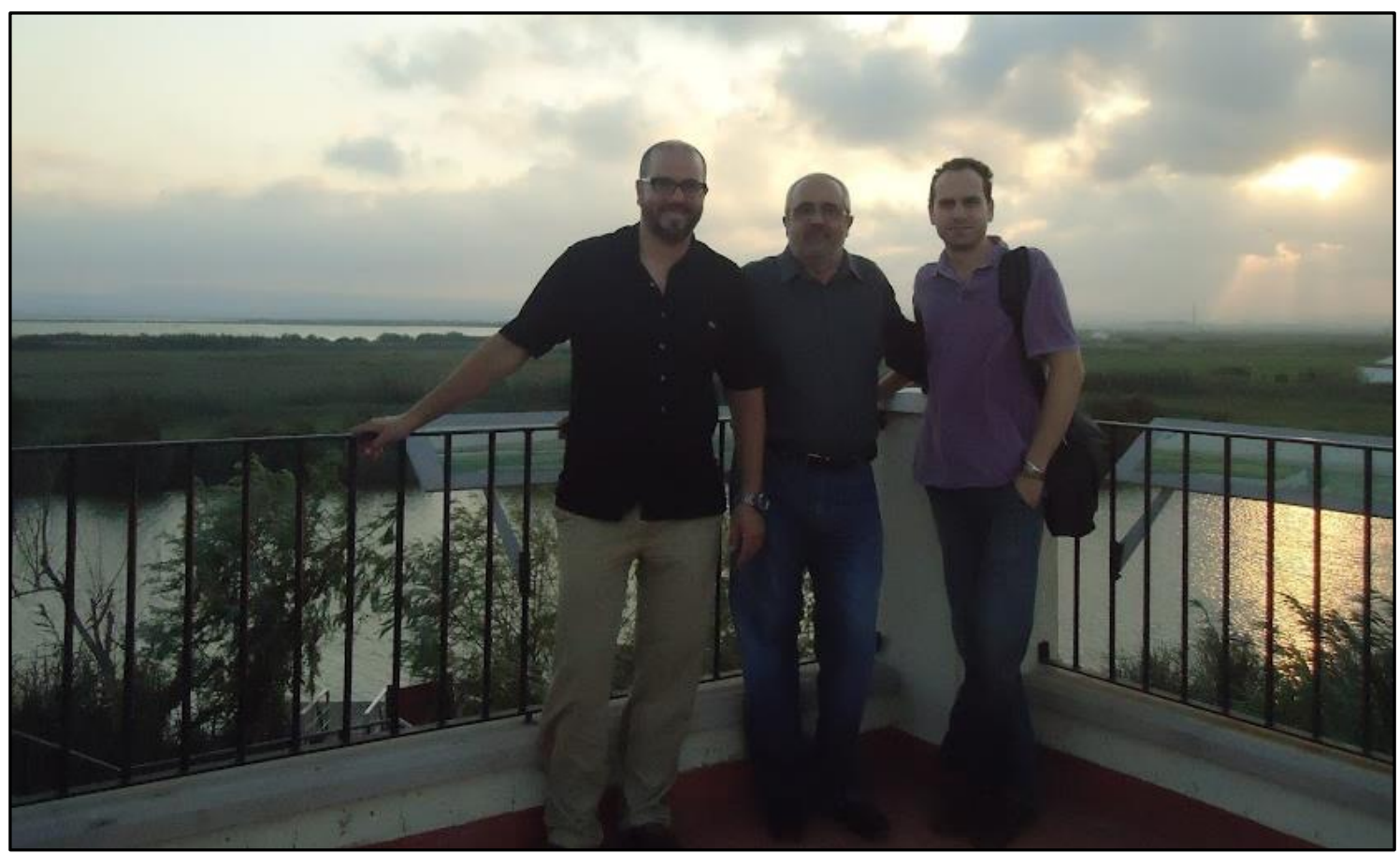

Joan Noguera es -y lo parece- de aquellas buenas personas que, además, aunque se empeñen no pueden dejar ser -y de parecer- buenas personas. Me atrevo a decir que cualquier persona que haya trabajado con nuestro amigo sabe perfectamente a qué me 
refiero: a ese deseo de ser útil, de ser amable, de comprender al otro, de tender puentes, de favorecer la colaboración. En palabras del propio Noguera: de buscar y obtener siempre el Win-Win.

Cuántas puertas ha abierto Joan Noguera con esa capacidad de transmitir solvencia profesional y empatía personal. Soy testigo privilegiado de su enorme potencia para diseñar y desarrollar propuestas para la colaboración con entidades, académicas o no, públicas y privadas, no solo en torno a lo que nos había unido en principio, el Centre Internacional de Gandia. También en el escenario internacional.

Si en nuestra tierra pusimos en marcha lo que llamamos unidades académicas, entre las cuales destacaba la dedicada al desarrollo local, Joan Noguera no por ello abdicó de sus proyectos españoles y europeos. Así fue que nos embarcamos en el trabajo con América Latina.

Chile, Brasil y la Rep. Dominicana fueron destino de viajes y estancias que siempre obedecían a haber contrastado el interés de la contraparte. Aunque con la república caribeña no tuvimos retornos positivos, pese a reunirnos con el presidente Medina y con los ministros de economía y de educación, los dos países del Cono Sur constituyeron éxitos importantes para la presencia, el intercambio y la transferencia desde la Universitat de València.

Tanto con el gobierno Bachelet en Santiago, como con la Intendencia de la Región de O'Higgins y con la Municipalidad de Rancagua firmamos convenios y proyectos tanto de transferencia de resultados de investigación como de formación de funcionarios de las administraciones públicas. Hasta un convenio musical surgió de aquella relación chilena: la Joven Orquesta de Rancagua hizo una estancia en Valencia trabajando con la Orquestra Filarmònica de la Universitat de València, que entonces dirigía el maestro Cristobal Soler.

Con Brasil trabajamos en el ámbito universitario, tanto con la Universidade de Rio Grande do Norte (sede de Natal), como con la Universidade de Paraiba (sede de João Pessoa). No obstante, el mayor éxito para la Universitat de València y para el IIDL fueron los diversos convenios de formación firmados con el Serviço Brasileiro de Apoio às Micro e Pequenas Empresas (SEBRAE), primero con los siete estados de la región Nordeste (Alagoas, Bahía, Ceará, Maranhão, Paraíba, Piauí, Pernambuco, Reio Grande do Noete y Sergipe), y luego con el SEBRAE nacional de Brasilia.

Aquellos convenios cristalizaron en el máster "Una visión territorial y sostenible del desarrollo. Métodos e instrumentos de acción institucional". Fue Joan Noguera quien diseñó e implementó aquel curso de posgrado, y lo hizo con tres etapas bien definidas: una primera, presencial en Brasil; una segunda, de formación on line para los técnicos designados por el SEBRAE (dos por cada estado); y, finalmente, una tercera, en la que esos mismos técnicos/alumnos realizaban una estancia de quince intensos días en la Universitat de València, dedicados a completar la formación en el aula y al intercambio de experiencias en sectores como el agroindustrial, la energía, el turismo y el apoyo a emprendedores locales. Tras la finalización de esa estancia, solo quedaba pendiente la presentación de los Trabajos Finales de Máster, para los que desde el IIDL nos trasladábamos de nuevo a Brasil para evaluarlos.

Fueron, pues, muchos los viajes que hicimos juntos; muchas horas de vuelo juntos y, a veces, todavía más de aeropuertos. Tuvimos entonces tantas y tantas ocasiones de profundizar en la amistad que ya había fraguado en Gandia. 
No obstante, no es la pluma del amigo la que escribe y firma estas líneas. Es la del colega, la del académico, profesor e investigador como él; la pluma que puede rubricar que Joan Noguera Tur es un universitario de los que he conocido pocos en las casi cuatro décadas en las que formo parte del cuadro docente de esta Universidad.

Sin embargo, pienso que su talla humana es todavía más grande. Joan Noguera es, al decir de Machado, un hombre en el buen sentido de la palabra, bueno. No sé si hay un logro más grande a alcanzar en la vida, pero creo que no.

Joan del Alcázar

12 de julio de 2021 


\section{JOAN NOGUERA; GRAN PROFESIONAL, MEJOR PERSONA. POR ADRIÁN FERRANDIS MARTÍNEZ (EDITOR INVITADO EN EL NÚMERO HOMENAJE A JOAN NOGUERA TUR)}

Como afirma el Profesor Javier Esparcia, en estas páginas iniciales de homenaje a nuestro querido Profesor Joan Noguera, un maestro nunca podrá olvidar a su primer discípulo, ni el primer discípulo podrá olvidar a su maestro. En ese sentido, tengo el honor y la satisfacción de ser el primer discípulo de mi maestro y mentor académico Joan Noguera.

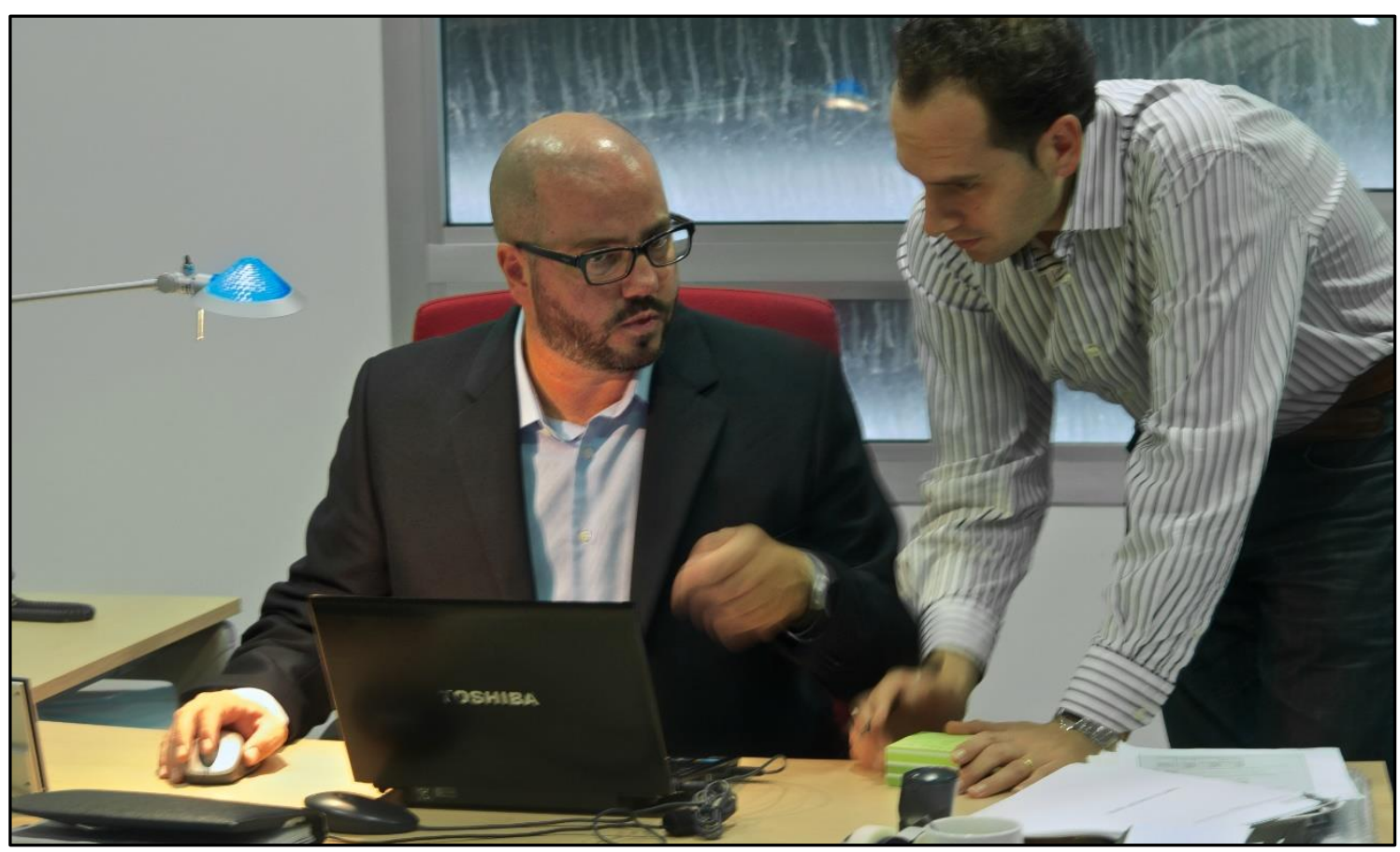

Se tiende a pensar que determinados encuentros se dan por casualidad, pero yo pienso que cuando dos personas están predestinadas a encontrarse, esto, tarde o temprano, se produce. Fue precisamente gracias a un encuentro casual, la primera vez que Joan y yo hablamos de una posible colaboración profesional. Fue, concretamente y no lo olvidaré nunca, el 3 de octubre de 2008, en las fiestas patronales de San Francisco de Borja, en Gandia, ciudad de la que ambos éramos vecinos. Coincidimos cruzando la pasarela que une el Passeig de les Germanies con el llamado Recinte Ferial. Joan me identificó y se acercó a mí para saludarme y preguntarme cómo me iba y a qué me dedicaba. Joan había sido mi profesor en la extinta Licenciatura de Geografía, en las asignaturas de Ordenación del Territorio y Geografía Regional de Europa. Nos emplazamos unos días más tarde para charlar sobre esa posible colaboración y, desde ese momento, nuestros caminos se unieron. La charla no fue muy larga, pero sí lo suficientemente intensa como para cautivarme y motivarme a participar en un proyecto común con intereses compartidos y con visos de futuro.

Por aquel entonces, Joan ya formaba parte de la Dirección del Centre Internacional de Gandia de la Universitat de València, junto con su entonces director, el profesor Joan del Alcázar. Su iniciativa y sus capacidades académicas e investigadoras le había llevado a iniciar un nuevo proyecto en Gandia, al mismo tiempo que asentaba las bases para crear 
su propio grupo de investigación liderando todo tipo de proyectos regionales, nacionales e internacionales.

En ese sentido, en el ámbito internacional participó como investigador principal en proyectos en el marco del ESPON Programme de la Unión Europea, vinculados con la temática de su especialización científica (desarrollo rural), tales como el "European Development Opportunities In Rural Areas (EDORA)", o el "Processes, Features and Cycles of Inner Peripheries in Europe (PROFECY)" en el que, además, actuó como Leader Partner. Igualmente, participó en proyectos del LIFE LONG LEARNIG Programme, con otro tipo de temáticas más variadas pero en directa relación con el desarrollo local, entre los que se pueden destacar algunos como el "Tools Pack For An Efficient Match Between Firms Demands, Vet Offer And Human Capital Capacities (LETS ADAPT)", el "Making European Policy Popular Through Challenge, Learning, Innovation, Cooperation: An Experiment On The Landscape Convention (ECLIC)" o el "Auditing The Sustainability Of Public Spaces (ASPIS)" entre otros. En todos ellos tuve el honor de colaborar con él. En esta faceta internacional, también actuó como asesor experto en los programas de asesoramiento para el desarrollo de la Organización para la Cooperación y el Desarrollo Económico (OCDE), particularmente en Chile.

Toda esta dinámica de trabajo en el ámbito internacional vino acompasada por multitud de proyectos de escala regional y local, mediante la firma de convenios con todo tipo de instituciones públicas, como los ayuntamientos de Gandia, Tavernes y Simat de la Valldigna, Cullera o el de la propia capital valenciana. Cabe destacar por su relevancia el "Plan Estratégico de Empleo, Emprendimiento y Formación de la Ciudad de València" y el del "Estudio de las Políticas de Ocupación en la 'Comarca del Montsià' (Tarragona)".

Con todo este volumen de proyectos, el grupo de investigación fue poco a poco consolidándose, incorporando a investigadores/as como la economista Mar Riera, el doctor y arquitecto Héctor del Alcázar, la doctora y agrónoma Mar Ortega, el geógrafo Giuseppe Escardaccione o la historiadora Indira Betancourt. Sin duda alguna, un caldo de cultivo fundamental que le llevó, junto al profesor Joan del Alcázar y a un servidor, a la creación del grupo de investigación en Sostenibilidad Local y Regional "LOCSUS", constituido oficialmente como "GIUV2017-402". Joan Noguera fue su director fundacional y siempre será para nosotros el gran referente científico.

Durante todo esto periodo de intenso trabajo de grupo, además, nuestro querido Joan pasó a ocupar otro cargo institucional importante, ya que fue elegido, en marzo de 2012, como Director del Instituto Interuniversitario de Desarrollo local, un centro de investigación y especialización de la Universitat de València, desde el que se trabaja en el sentido más amplio del desarrollo local. Este cargo lo ostentó durante seis intensos años, hasta junio de 2018, momento en el que se vio obligado a su retiro prematuro y forzado por motivos de salud. En el trascurso de esta etapa como director, Joan fue el impulsor de iniciativas importantes para la consolidación del Instituto, como el impulso de la revista científica TERRA (en la que se enmarca este número homenaje), la estabilización de una estructura administrativa y de grupos de investigación oficialmente reconocidos, o el posicionamiento del propio instituto como un importante referente académico e institucional.

Su profesionalidad demostrada es, sin duda, digna de alabar; por su constancia, dedicación, trabajo, humildad, deseo de superación y compromiso institucional. Con todo y con eso, a pesar de todas estas poderosas virtudes profesionales, lo que más ha impactado siempre a las personas que le hemos rodeado en este escenario académico, es 
su calidad humana. Remarcando una de las ideas del profesor Joan del Alcázar es estas mismas páginas, Joan Noguera es de aquellas buenas personas que lo es -y lo parece-, y, además, aunque se empeñen, no pueden dejar ser -y de parecer- buenas personas.

Todos esos valores como profesional y como ser humano son los que están guiando y guiarán a nuestro grupo de investigación, su grupo, con el objetivo de seguir cumpliendo con nuestra obligación social como personal docente e investigador, y para seguir ofreciendo oportunidades a los más jóvenes desde una dinámica positiva fundamentada en la que podríamos denominar filosofía Noguera: intereses compartidos y Win-Win.

Como discípulo suyo no es que nunca lo olvidaré, sino que, como un hijo respecto a su padre, sus consejos me acompañan y me guiarán en esta complicada pero apasionante vida académica.

Gracias por todo Joan, profesor y maestro, nuestros caminos están unidos para siempre.

Adrián Ferrandis

14 de julio de 2021 